\title{
Radiowave propagation measurements in Nigeria (preliminary reports)
}

\author{
S. E. Falodun • P. N. Okeke
}

Received: 16 March 2012 / Accepted: 4 September 2012 /Published online: 6 October 2012

(C) The Author(s) 2012. This article is published with open access at Springerlink.com

\begin{abstract}
International conferences on frequency coordination have, in recent years, required new information on radiowave propagation in tropical regions and, in particular, on propagation in Africa. The International Telecommunications Union (ITU-R) initiated 'radio-wave propagation measurement campaign' in some African countries some years back. However, none of the ITU-initiated experiments were mounted in Nigeria, and hence, there is lack of adequate understanding of the propagation mechanisms associated with this region of the tropics. The Centre for Basic Space Science (CBSS) of NASRDA has therefore embarked on propagation data collection from the different climatic zones of Nigeria (namely Coastal, Guinea Savannah, Midland, and Sahelian) with the aim of making propagation data available to the ITU, for design and prediction purposes in order to ensure a qualitative and effective communication system in Nigeria. This paper focuses on the current status of propagation data from Nigeria (collected by CBSS), identifying other parameters that still need to be obtained. The centre has deployed weather stations to different locations in the country for refractivity measurements in clear atmosphere, at the ground surface and at an altitude of $100 \mathrm{~m}$, being the average height of communication mast in Nigeria. Other equipments deployed are Micro Rain Radar and Nigerian Environmental and Climatic Observing Program equipments. Some of the locations of the measurement stations are Nsukka $\left(7.4^{\circ} \mathrm{E}, 6.9^{\circ} \mathrm{N}\right)$, Akure $\left(5.12^{\circ} \mathrm{E}, 7.15^{\circ} \mathrm{N}\right)$, Minna $\left(6.5^{\circ} \mathrm{E}, 9.6^{\circ} \mathrm{N}\right)$, Sokoto $\left(5.25^{\circ} \mathrm{E}, 13.08^{\circ} \mathrm{N}\right)$, Jos $\left(8.9^{\circ} \mathrm{E}\right.$, $\left.9.86^{\circ} \mathrm{N}\right)$, and Lagos $\left(3.35^{\circ} \mathrm{E}, 6.6^{\circ} \mathrm{N}\right)$. The results obtained
\end{abstract}

S. E. Falodun $(\bowtie)$

Department of Physics, Federal University of Technology, PMB 704,

Akure, Nigeria

e-mail: besfal@yahoo.com

P. N. Okeke

Centre for Basic Space Science CBSS-NASRDA,

Nsukka, Nigeria from the data analysis have shown that the refractivity values vary with climatic zones and seasons of the year. Also, the occurrence probability of abnormal propagation events, such as super refraction, sub-refraction, and ducting, depends on the location as well as the local time. We have also attempted to identify and calculate the most important propagation factors and associated data, such as $k$ factor, that are relevant in considerations of propagation in tropical regions like Nigeria.

\section{Introduction}

Propagation data are statistically representative of propagation behaviour and associated conditions in both the troposphere and the ionosphere throughout the world. The planning of broadcasting services above $30 \mathrm{MHz}$ has been based on Recommendation 370 of the 'International Telecommunication Union (ITU-R)'. However, most of the propagation curves and formulas used are derived from measurements performed in Europe, North America, and Japan. Although the climate is different in Africa, the planning of radio services in Africa has been based largely on these data and curves. However, research results (e.g. Hughes 1988) have shown that optimized planning of radio services in Africa requires data which take account of the specific climatic conditions. As a result, the ITU started a radiowave propagation measurement campaign for Africa in 1984. A number of experiments/projects were carried out in some locations in Africa.

Unfortunately, none of these experiments were mounted in Nigeria, and hence, there were no adequate propagation data in the country for planning. As a consequence, there is no proper understanding of the propagation mechanisms associated with this region of Africa.

In response to the ITU-R's call, many researchers in Nigeria have made substantial contribution to the data base (Falodun and Ajewole 2006; Kolawole and Owonubi 1982). However, the propagation data that have been acquired locally have been, largely, by radiosonde. Until recently, 
researchers in radiowave propagation have relied on these radiosonde data for their study in radio communications. But, the radiosonde data are not well suited for determining the refractivity profile in the lower $100 \mathrm{~m}$ of the troposphere because ascent speed restricted only by the free lift is too large for accurate and detailed measurements. The variation of the measured values is usually too small due to the time constants of the sensors which are large compared with the travelling time inside the atmospheric layer (Bean and Dutton 1968).

The current research effort by the Centre for Basic Space Science, CBSS, is therefore aimed at making an input to the data base by engaging in in-situ measurements of the relevant parameters. This is aimed at enhancing the quality of radio signals in Nigeria through adequate planning.

\subsection{Presentation of basic propagation data}

Radiowave propagation data represent the fundamental basis upon which studies of propagation phenomena are built. The analysis of suitably large bodies of data leads to an understanding of the various propagation characteristics observed and to an appreciation of the influence of the neutral atmosphere on radiowave propagation. Models can then be developed allowing propagation to be predicted as a function of the prevailing conditions of the propagation medium concerned (Grabner et al. 2003b).

The propagation data give information relating to clear air effects concerning (1) terrestrial line-of-sight (LOS) paths, (2) earth-space (ES) paths (fixed, mobile, and broadcasting), and (3) evaluation of interference and signal levels. In relation to radiowave propagation, the prediction methods that are usually used include (1) attenuation due to atmospheric gases (LOS and ES paths), (2) diffraction fading due to path variations (LOS), (3) multi-path effects, focusing/defocusing, ray bending, scintillation (LOS and ES), (4) depolarization (LOS paths), and (5) super refractive effects and ducting.

\section{Data collection by CBSS}

The CBSS, Nsukka, embarked on atmospheric data collection some years ago with particular interest in propagation data. The following research equipments are being used by the centre for measurements and data collection for propagation studies at different locations in Nigeria.

1. Nigerian Environmental and Climatic Observing Program (NECOP) - to monitor real time climatic and environmental hazards in Nigeria

2. Automatic weather stations - for propagation studies

3. Rain radar-for rain attenuation studies

4. Field-strength measurements - for propagation studies
Some of the meteorological parameters that are currently being measured include wind speed, wind direction, rainfall, atmospheric temperature, relative humidity, atmospheric pressure, ultraviolet radiation, solar radiation, signal strength, and rain rate, etc.

\subsection{The Nigerian Environmental Climatic Observing Program}

NECOP is a project designed to establish a network of meteorological and climatological observing stations, spatially located across Nigeria as shown in Fig. 1. The aim of NECOP is to create a network of stations that can carry out simultaneous basic measurements of meteorological and climatological variables, in real time, through telemetry technology, with 5-min update cycles. The project is being executed in collaboration with the Centre for Climatic Research, DE, USA; NIMET; and Nigerian universities.

A typical NECOP station is shown in Fig. 2. The equipment can measure air temperature (in degrees Celsius), relative humidity (in percent), precipitation (in millimetres), atmospheric pressure (in millibars), wind speed (in metres per second), direction (in degrees $\mathrm{N}$ ), solar radiation (in watts per square metre), soil moisture (in percent), soil temperature (in degrees Celsius), and rain rate (in millimetres per minute).

All the existing stations across the country are commanded and controlled from a central location or server. The system server is located in CBSS, Nsukka.

\subsection{Refractivity measurements}

Adequate planning of radio propagation requires a good knowledge of the variation pattern of the atmospheric parameters (conditions) during the different months of the year and an assessment of their potential effects on a regional radio range and propagation paths. The calculations involved include statistics and seasonal variations of surface refractivity and vertical refractivity gradients for the lowest $100 \mathrm{~m}$ height.

The refractive index $n$ of air depends on the atmospheric pressure $P$ (in millibars), the temperature $T$ (in kelvins), and the water vapour pressure $e$ (in millibars) of the atmosphere (Hall 1979). The radio refractivity, $N$, and the refractive modulus, $M$ for air, for frequencies up to $100 \mathrm{GHz}$, are given by the ITU-R formula [ITU-R (1987)] in Eqs. 1 and 2.

$N=77.6 \frac{P}{T}+3.73 \times 10^{5} \frac{e}{T^{2}}$

$M=(n-1) \times 10^{6}+\frac{h}{R} \times 10^{6}$

where $P$ is the atmospheric pressure; $e$ is the water vapour pressure which can be calculated from the relative humidity 
Fig. 1 Map of Nigeria showing the locations of NECOP stations

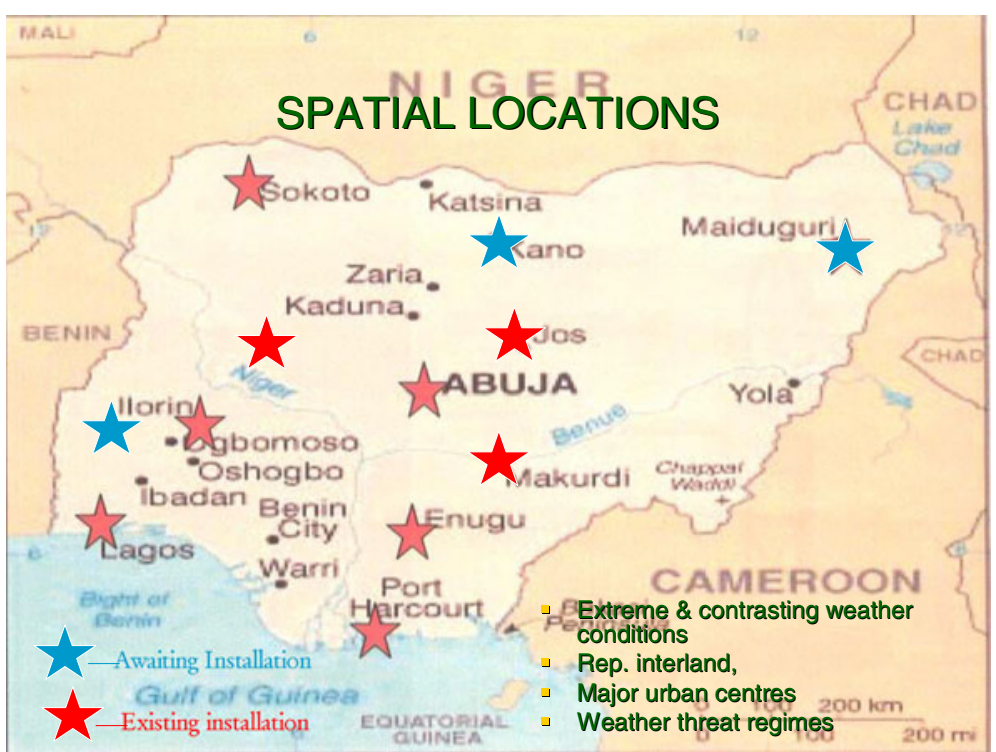

and the saturation vapour pressure, using the relationship described in Rec. ITU-R.P. 453-9 (2004); and $T$ is the absolute temperature. Also, $h$ (in kilometres) is the height

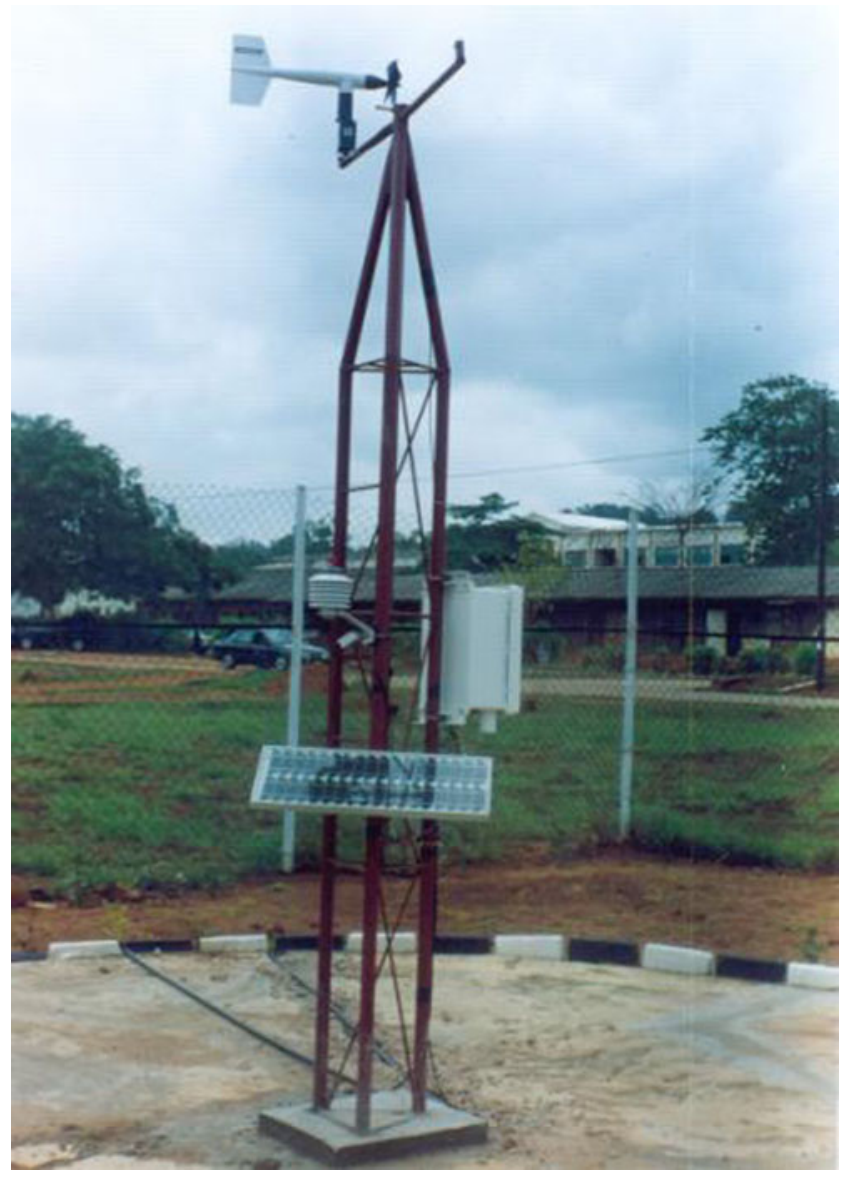

Fig. 2 A typical NECOP station of the atmospheric layer above the earth's surface, and $R$ (in kilometres) is the radius of the earth.

In terms of refractive index, whenever the vertical refractivity gradient, $d N / d h$, of the atmosphere is less than the standard refractivity gradient of $-40 \mathrm{~N}$-units $/ \mathrm{km}$, the radio ray will undergo super refraction. On the other hand, the radio ray will be sub-refracted whenever $d N / d h$ is greater than $-40 \mathrm{~N}$-units $/ \mathrm{km}$. If $d N / d h$ in a layer of the atmosphere is equal to $-157 \mathrm{~N}$-units $/ \mathrm{km}$, the curvature of the path is equal to that of the earth. On occasions when meteorological conditions are such that the vertical gradient is less than $-157 \mathrm{~N}$-units $/ \mathrm{km}$, trapping or ducting of the rays may occur depending on the wavelength and duct thickness (Barclay 2003).

A consequence of super refraction and ducting is the extension of the radio range, which sometimes leads to radio interference between neighbouring transmission links. On the other hand, sub-refraction reduces radio horizon.

For an ideal condition of the atmosphere, the atmosphere is uniformly stratified, and the vertical gradient of the refractive index is assumed constant and defined by

$k=\frac{1}{1+R \frac{d n}{d h}}=\frac{1}{1+R \frac{d N}{d h} 10^{-6}}=\frac{10^{6}}{R \frac{d M}{d h}}$

where $k$ is the effective earth-radius factor.

In temperate climates, the average variation of the refractive index near the ground is about $-40 \mathrm{~N} / \mathrm{km}$ (CCIR, 1974). Then, putting $R=6,370 \mathrm{~km}$ gives a value of $k=4 / 3$. It is therefore, common practice to use a $4 / 3$ earth radius in the design of microwave communication links.

Furthermore, because of the convenience of the $4 / 3$ effective earth's radius, it has been widely used in radio propagation work and the radar. However, the procedure has several 
limitations. It is only an average value and may not be used for purposes other than general computation. In addition, the assumption that $n$ decreases linearly with height is in disagreement with the experimentally observed refractive index structure of the atmosphere (Bean and Dutton 1968). It is therefore necessary to use data which are representative of a particular locality to estimate the appropriate values of $k$ for a given region.

\subsubsection{Method and instrumentation}

The air temperature (in degrees Celsius), the water vapour pressure (in percent), and the barometric pressure (in millibars) were measured simultaneously at the ground surface and at a height of $100 \mathrm{~m}$ above the ground surface. The equipment (i.e. 'Integrated Sensor Suite') was positioned at a pre-determined height of $100 \mathrm{~m}$ on a communication mast, and the 'data logger' which is attached to the console allows the data to be logged in at a regular time interval of $30 \mathrm{~min}$. Another set of the measuring equipment was positioned at the ground surface to measure the surface values of these parameters. The data obtained were used to calculate the refractivity values and the mean gradient of N-profile for this range of propagation path, using Eqs. 1 and 2.

The present treatment of the parameters is concerned with the degree to which the average refractivity structure reflects the gross differences in climate over Nigeria. Furthermore, the diurnal and the seasonal range graphs of the refractivity at the earth's surface and at an altitude of $100 \mathrm{~m}$ shed light upon climatic characteristics of the parameters. The applications of this information are found in practical problems, such as the prediction of radio field strength and the refraction of radiowaves.

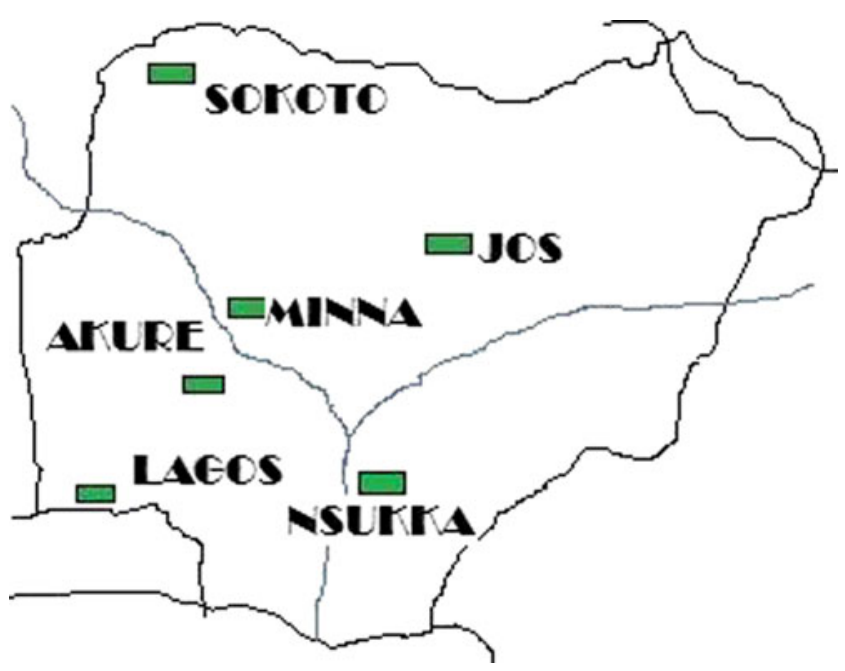

Fig. 3 Location of the measurement stations in Nigeria
A better characterization of the refractivity gradient is thus obtained by the in-situ measurements used for this study. These values are also used in the analysis of the occurrence probability of clear air phenomena such as super refraction and ducting. Figure 3 shows the location of the measurement sites across Nigeria.

\subsubsection{Instrumentation}

The device used for the measurements is the Davis 6162 wireless Vantage Pro Plus, manufactured by Davis Instruments, Hayward, CA, USA. It is equipped with the Integrated Sensor Suite (ISS) (Fig. 4), a solar panel (with an alternative battery), and wireless console, which provides the user interface, data display, and analogue-to-digital conversion.

The device uses the combination of fan-aspiration to minimize the effects of solar radiation-induced temperature error. The ISS houses the external sensor array for measurements of pressure, temperature, relative humidity, ultraviolet index, solar radiation, and rainfall rate among others. The console is connected to a computer through the data logger from which the stored data are downloaded. The frequency of transmission of the ISS is $868.0-868.6 \mathrm{MHz}$, and the error margin of the device for temperature, pressure, and relative humidity are $\pm 0.10{ }^{\circ} \mathrm{C}, \pm 0.5 \mathrm{hpa}$, and $\pm 2 \%$, respectively. The data from the ISS are transmitted to the console via radio, as shown in the block diagram in Fig. 5.

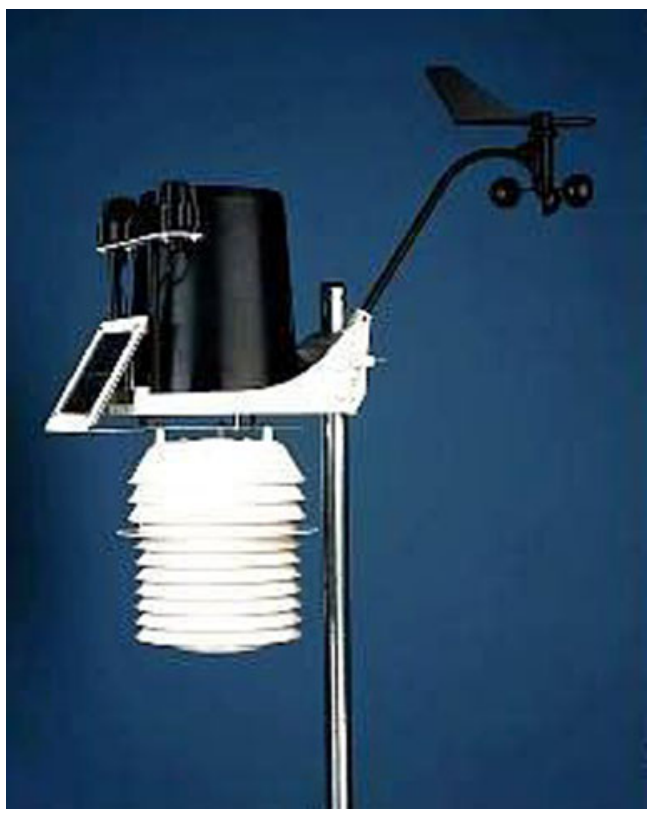

Fig. 4 The Integrated Sensor Suite (ISS) 


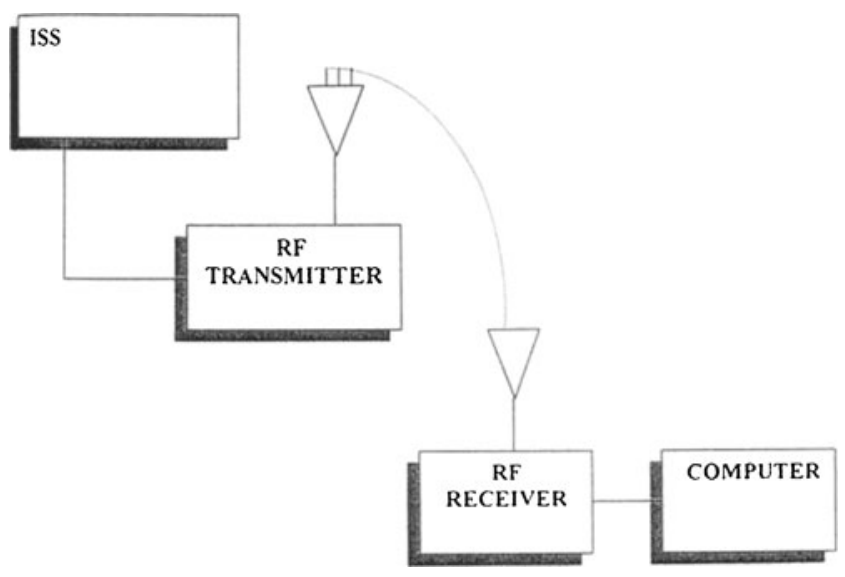

Fig. 5 The block diagram of the equipment set-up

\section{Results and discussion}

\subsection{Refractivity values and derived characteristics}

The basic data employed for the calculation of the radio refractivity were radio-meteorological data obtained by in situ measurements at stations located at Nsukka $\left(7.4^{\circ} \mathrm{E}\right.$, $\left.6.9^{\circ} \mathrm{N}\right)$, Akure $\left(5.12^{\circ} \mathrm{E}, 7.15^{\circ} \mathrm{N}\right)$, Minna $\left(6.5^{\circ} \mathrm{E}, 9.6^{\circ} \mathrm{N}\right)$, and Sokoto $\left(5.25^{\circ} \mathrm{E}, 13.08^{\circ} \mathrm{N}\right)$, in Nigeria. These stations were carefully selected to represent the climatic regions in Nigeria. For example, Nsukka is representative of Coastal climate while Minna and Sokoto are representatives of Guinea Savannah and Shelia Savannah, respectively.

The data cover the two main seasons of the years considered (i.e. the wet and dry seasons). The meteorological data used for the analysis include the atmospheric pressure $P$ (in millibars), the temperature $t$ (in degrees Celsius), and the relative humidity $R / H$ (in percent). The measurements were made every

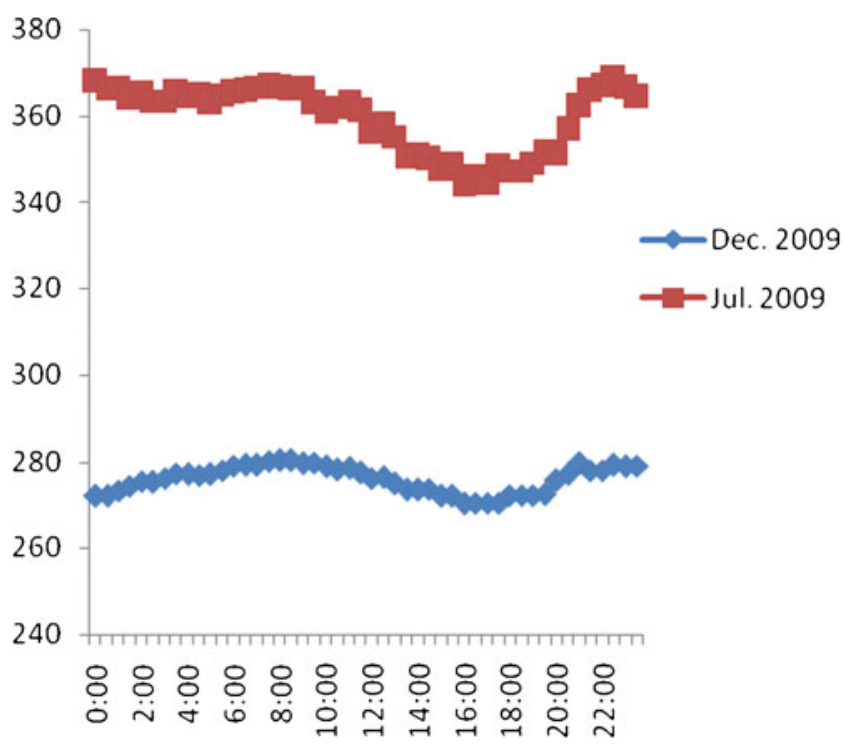

Fig. 6 Typical diurnal variation of refractivity values at Sokoto

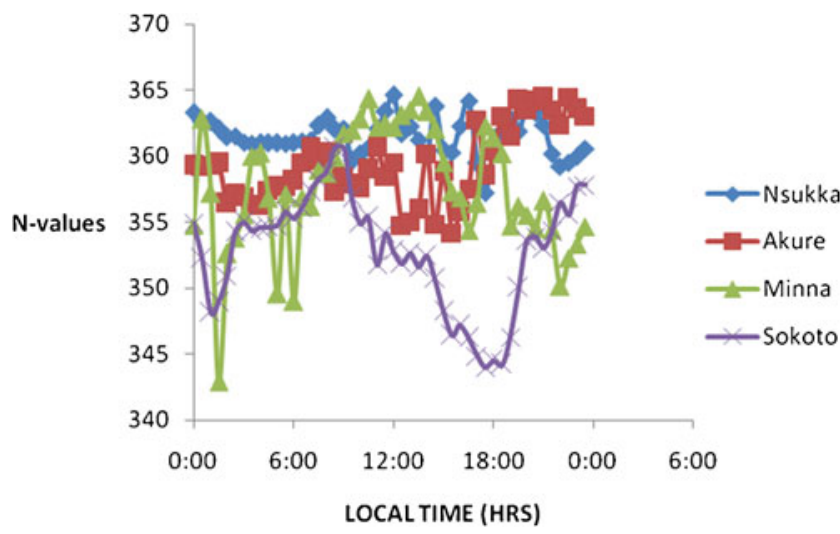

Fig. 7 Typical diurnal refractivity variation for the stations, August 2009

30 min and round the clock for the periods considered (i.e. February 2007 to March 2009 for Nsukka, November 2007 to October 2009 for Minna, January 2007 to December 2009 for Akure, and June 2008 to March 2010 for Sokoto).

For estimation of the refractivity effects, the following parameters defined in ITU-R Rep. 563 were evaluated from the refractivity profile.

- Surface value of radio refractivity, $N_{\mathrm{s}}$ : this is the refractivity determined at ground level of the station.

- Refractivity at $100 \mathrm{~m}$ height, $N_{1}$ : the refractivity determined at $100 \mathrm{~m}$ height above the ground level.

- Change of radio refractivity, $\Delta N$ : this is the difference between the surface refractivity, $N_{\mathrm{s}}$, and the refractivity measured at an altitude of $100 \mathrm{~m}$ above ground level, $N_{1}$ :

$\Delta N=N_{s}-N_{1}$

The refractivity gradients were calculated between the earth's surface and the $100 \mathrm{~m}$ height.

The result obtained for each station shows that the diurnal variation of the refractivity follows the same pattern for both dry and wet seasons with the values during the rainy season

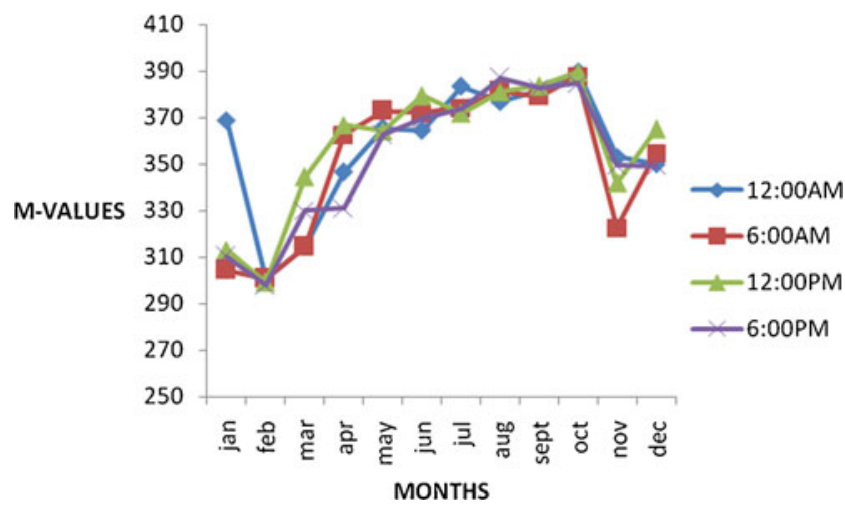

Fig. 8 Example of the seasonal variation of the mean monthly distribution of refractive modulus for morning (6:00 AM), evening (6:00 PM), and night (12:00 AM) at altitude of $100 \mathrm{~m}$ in a savannah (Minna) station 
Table 1 Probability of occurrence of propagation phenomena

\begin{tabular}{lcc}
\hline & Rainy season (\%) & Dry season (\%) \\
\hline $\begin{array}{l}\text { Probability of occurrence } \\
\text { of sub-refraction }\end{array}$ & 20 & 5 \\
$\begin{array}{l}\text { Probability of occurrence } \\
\text { of super refraction }\end{array}$ & 80 & 95 \\
$\begin{array}{l}\text { Probability of occurrence } \\
\text { of ducting }\end{array}$ & 31 & 15 \\
\hline
\end{tabular}

being higher; the typical result is shown for Sokoto in Fig. 6. The maximum $N$ values are observed in morning and night hours, while its minimum values are fixed between $3 \mathrm{pm}$ and $6 \mathrm{pm}$. The higher values obtained during the morning and night hours can be attributed to the high values of the relative humidity recorded for these hours of the day, while the lower refractivity values in the afternoon can be attributed to the low relative humidity which resulted from the high temperature associated with the afternoon hours. The comparisons of the refractivity values and their diurnal variations at the different climatic regions have been plotted in Fig. 7. The figure shows that the values at Nsukka are the highest followed by those obtained from Akure. But the range of values obtained for Minna and Sokoto is higher than those obtained for Nsukka and Akure. As observed in Fig. 6, the variation is similar for the stations. For example, there are high values in the morning and evening hours while the values are relatively lower in the afternoon hours. It was also observed that as the location goes into the interland, the absolute values reduce while the range of values increase.

Typical seasonal variations of the refractivity for Minna are shown in Fig. 8. The figure reflects similarities in the variation pattern at different hours of the day. The values are higher during the rainy months of June to October at both these savannah areas of the country.

The results obtained for Nsukka have shown that large negative refractivity gradients were obtained for most of the refractivity profiles measured at the station as observed in Fig. 9. The values obtained revealed that the propagation conditions are super refractive at both seasons of the year. However, some events of sub-refraction are also observed (see Table 1).

Cumulative probability curves were also prepared for the refractivity gradients obtained for this station. These are presented in Figs. 10 and 11. Deductions from the curves are presented in Table 1 . The results show that during the rainy season, the propagation layer $0-100 \mathrm{~m}$ is super refractive most of the time with the probability of occurrence of duct being $31 \%$.

The implications of these results are quite significant on the propagation conditions of microwave signals through the atmosphere in this locality. For example, in a super refractive condition, the path loss is smaller than in the standard atmosphere. Deductions from the cumulative probability curve show that the occurrence of super refraction is $80 \%$ in the rainy season. The high percentage of occurrence suggests that the worst month with respect to interference is likely to occur in the rainy season when $N$ values are relatively higher. This observation agrees with the results reported by Bean and Dutton (1968) and Grabner et al. (2003a). According to the reports, the probability of large variations due to anomalous propagation is very high in the rainy season owing to the fact that the atmospheric layers are formed above large, flat lakes which are filled only during the rainy season. This situation encourages high 'relative humidity' as a result of evaporation from the surface of the lakes. Super refractive gradients are responsible for generally extended service horizon and could cause interference between widely separated radio circuits
Fig. 9 Typical refractivity gradient (in N-units/kilometre) plotted for Nsukka, December, 2007

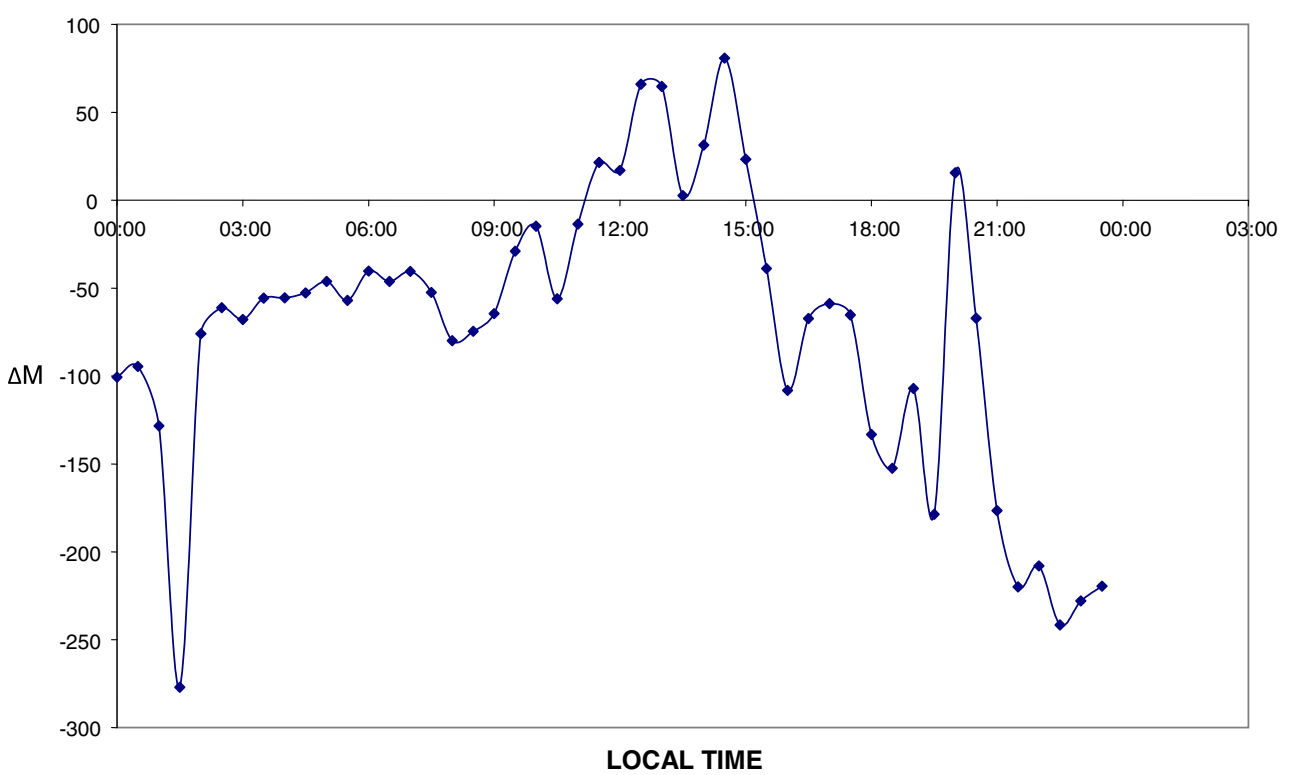


Fig. 10 Cumulative distribution curve for wet condition

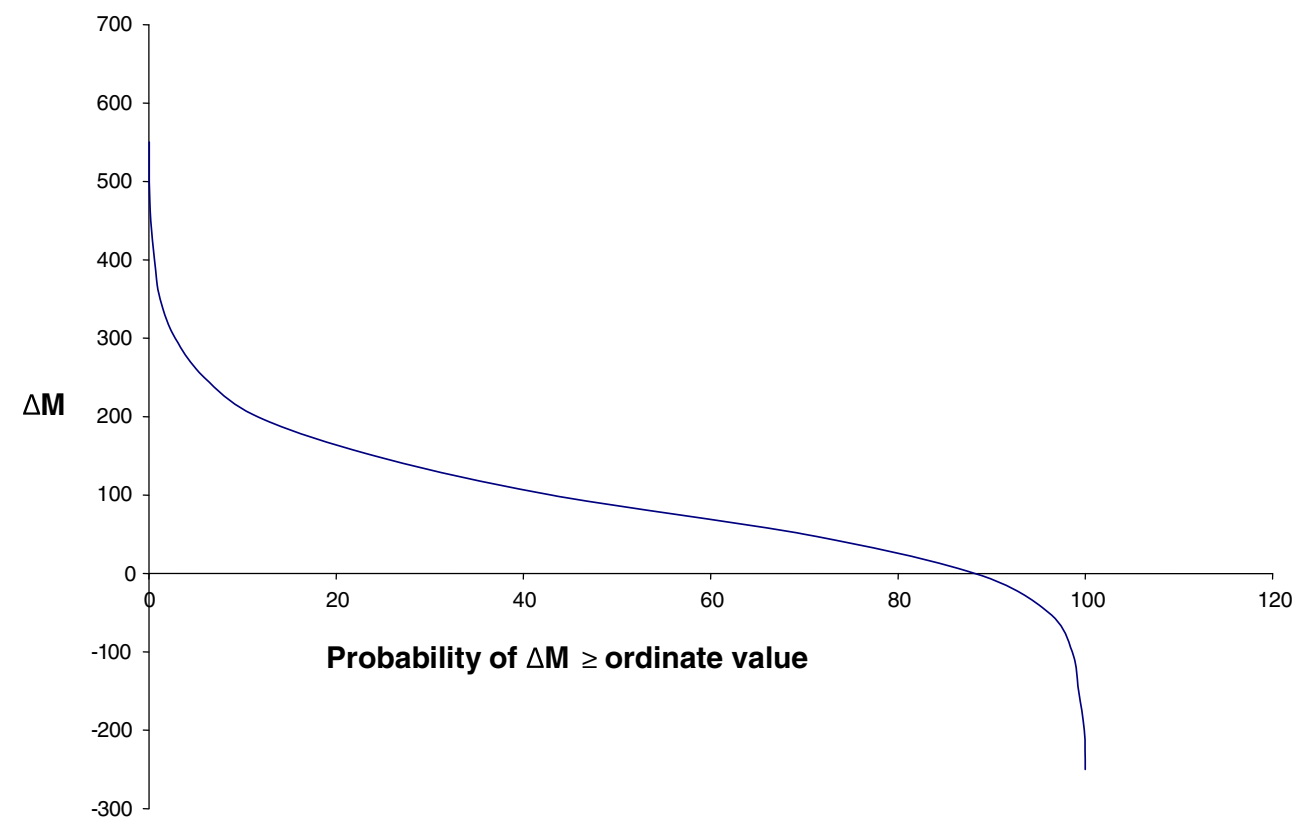

operating on the same frequency. This phenomenon is commonly observed in this locality especially during the raining season.

Another abnormal phenomenon of interest is subrefraction. A sub-refractive layer could be present during the day, especially at the time of maximum surface heating. The results for Nsukka have shown that the probability of occurrence of sub-refractivity is $20 \%$ in the rainy season while the probability reduces to $5 \%$ during the dry season. It is therefore possible to experience signal loss or fading in this locality as a result of sub-refraction.

A consequence of sub-refraction on a nearly horizontal path is that the wave trajectory comes nearer to the ground. In extreme cases, if there is an obstacle (for instance a hill) along the link, the transmitted signal level can be severely reduced by diffraction resulting in obstruction fading (Bonkoungou and Low 1993).

On the other hand, a large negative refractivity gradient causes ducting, the possible effects of which are prolonged space wave fade-outs, multi-path fading, and excessive field strengths at distances many times the radio horizon.

The histogram plots shown in Figs. 12, 13, and 14 give the summary of the occurrence percentages of super refraction, sub-refraction, and ducting events for the stations at Sokoto, Akure, and Minna, respectively. As shown in Fig. 13, results for Akure station show that the rainy months of July and August are dominated by super refractive events with the percentage of occurrence ranging between 56 and $68 \%$. Duct activity was recorded for about $40 \%$ of events in August and September. Furthermore, the dry months of
Fig. 11 Cumulative distribution curve for dry condition

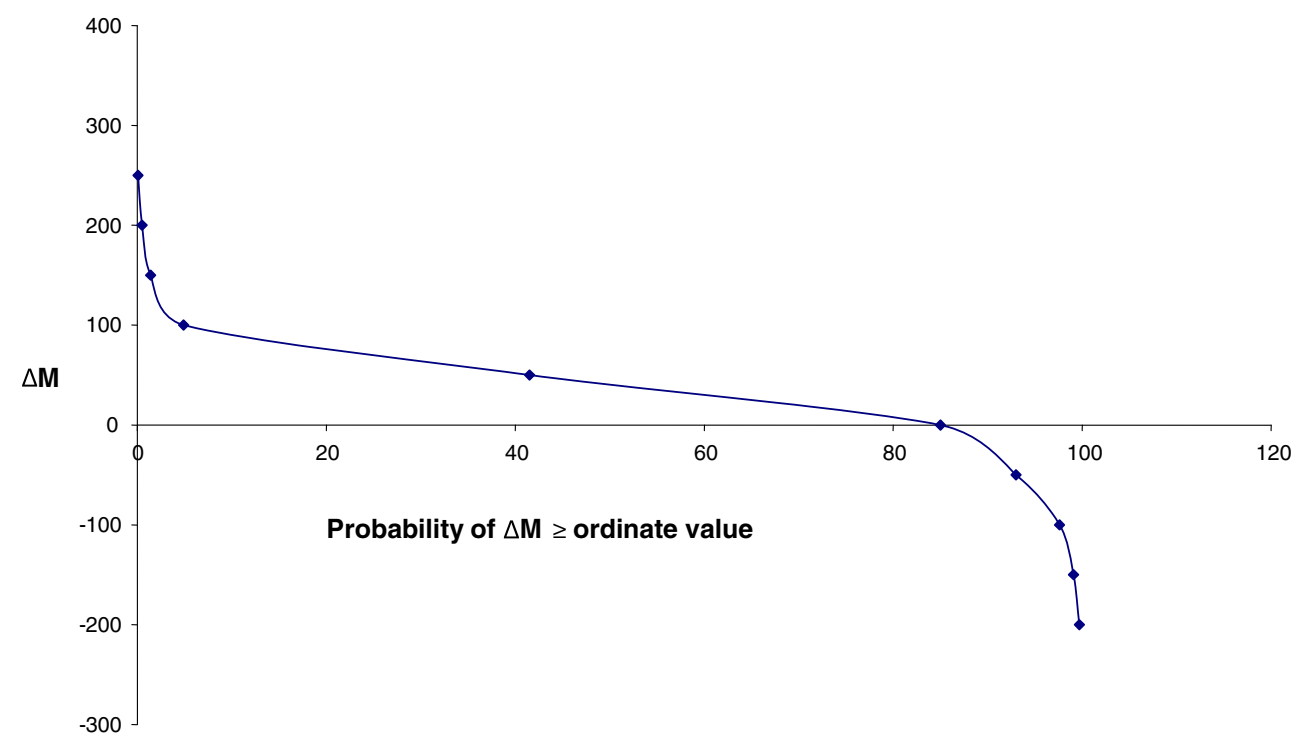




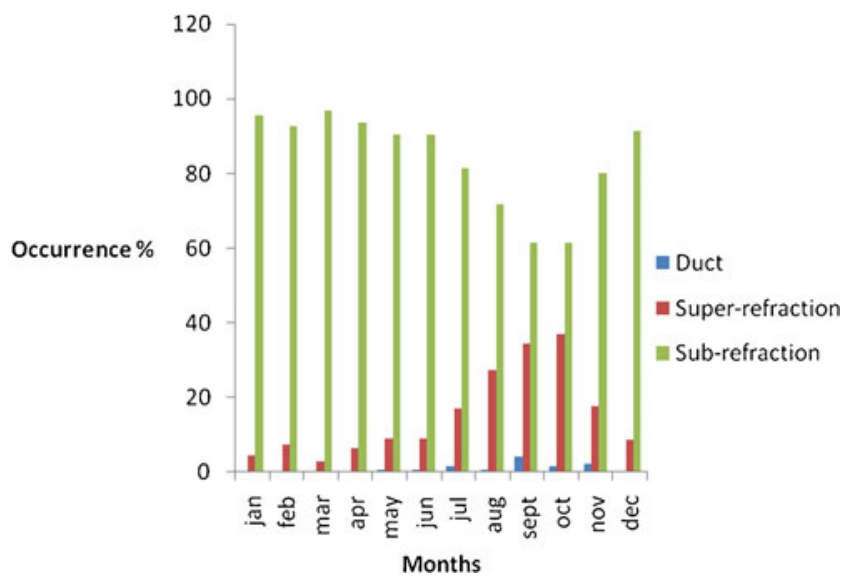

Fig. 12 Summary of occurrence of ducting, super refraction, and subrefraction in Sokoto, Nigeria. These propagation conditions are calculated in terms of $\mathrm{N}$-index and the gradient intervals are: ducting $\mathrm{dN} / \mathrm{dh},<-157$; super refraction $\mathrm{dN} / \mathrm{dh},-40$; sub-refraction $\mathrm{dN} / \mathrm{dh}$, $>-40$

January and February were dominated by sub-refractive activity with the percentage of occurrence above $60 \%$.

The results obtained for the station at Sokoto show that sub-refraction dominates most of the time with the occurrence percentage of $80 \%$. Super refraction was also observed during the rainy months of August, September, and October. A very low percentage of duct occurrences was also observed in the month of September, which is the peak of the rainy season in this locality.

The seasonal and diurnal variations of the wet term in the refractivity Eq. 1 have been observed to correlate with the variation of VHF and UHF field strengths (Owolabi and Williams 1970). This observation could partly explain the low signal level often received in the afternoon periods, especially from distant stations. For example, the results for the Minna station shows that, in the time window 3:00 PM to 6:00 PM local time for the rainy months, the potential for the

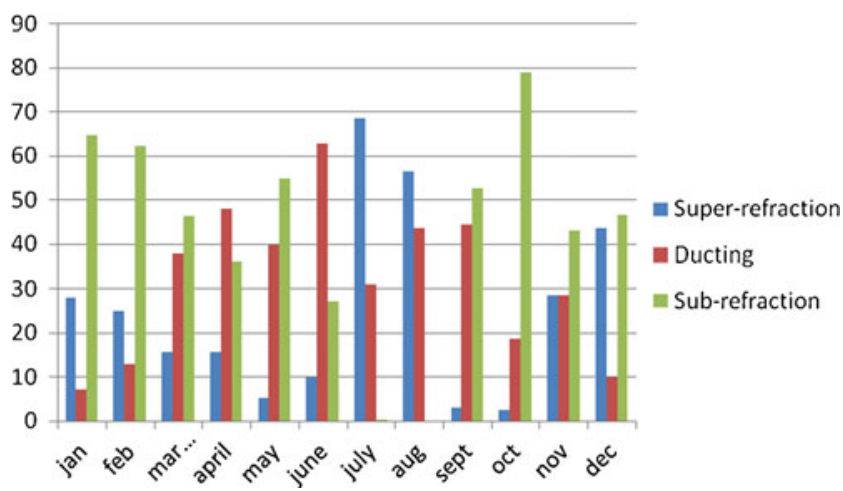

Fig. 13 Summary of occurrence of ducting, super refraction, and subrefraction in Akure, Nigeria. These propagation conditions are calculated in terms of $\mathrm{N}$-index, and the gradient intervals are: ducting $\mathrm{dN} / \mathrm{dh},<-157$; super refraction $\mathrm{dN} / \mathrm{dh},-40$; sub-refraction $\mathrm{dN} / \mathrm{dh}$, $>-40$

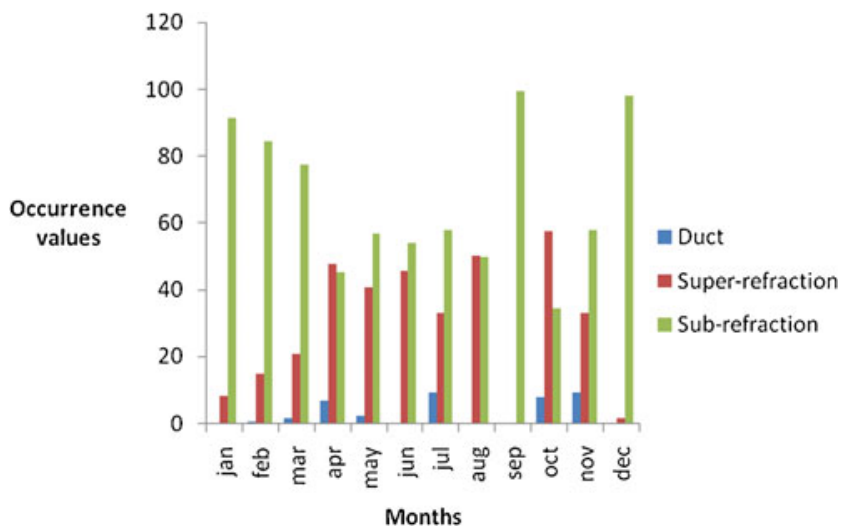

Fig. 14 Summary of occurrence of ducting, super refraction, and subrefraction in Minna, Nigeria. These propagation conditions are calculated in terms of $\mathrm{N}$-index, and the gradient intervals are: ducting $\mathrm{dN} / \mathrm{dh},<-157$; super refraction $\mathrm{dN} / \mathrm{dh},-40$; sub-refraction $\mathrm{dN} / \mathrm{dh}$, $>-40$

occurrence of interference between broadcasting stations in Minna and other stations from far away, transmitting on the same frequency, will be greatly reduced due to the lowest refractivity in this time window.

The propagation factors, i.e. $k$ factors, were also derived for the stations using the mean values of the refractivity gradient $\alpha$ for all the data sets for each of the stations. Equation 3 was then used to calculate the $k$ factor with $R=6,370 \mathrm{~km}$.

The $k$ factor derived for the station at Nsukka is 1.58 while the values are 1.51 and 1.34 for the stations at Akure and Sokoto, respectively. These values have shown that the ITU-R value of $k=4 / 3$ is not appropriate for these locations. The values obtained for the stations are generally higher than the value of $k=4 / 3$ for the temperate climate.

\section{Summary}

CBSS, Nsukka, has embarked on radiowave propagation experiments in different locations in Nigeria. The measurements are ongoing, and it covers both the rainy and dry seasons of the year.

The results for stations that have at least 2 years of data have been presented in this report, and the data analysis has shown that the refractivity values vary with climatic zones as well as the seasons of the year.

The $k$ factor derived for the station at Nsukka is 1.58 while the values are 1.51 and 1.34 for the stations at Akure and Sokoto, respectively. These values have shown that the ITU-R value of $k=4 / 3$ is not appropriate for these locations in Nigeria.

The refractivity measurements made so far at the different climatic zones of Nigeria have shown that the propagation conditions are super refractive $(\Delta N>40 \mathrm{~N}$-units $/ \mathrm{km})$ during the rainy seasons. 
These experiments constitute our initial efforts towards the contribution to the process of acquiring more knowledge about radiowave propagation in Nigeria. Based on these results and subsequent results to be obtained, modifications to the propagation zones will be proposed to the ITU-R.

The measurements are ongoing, and the refractivity measurements would be performed parallel to the VHF measurements at the receiver site at each geographic zone of Nigeria for different seasons of the year. The acquired data would then be used to prepare the propagation curves required for the planning of radio services in Nigeria.

\section{Remarks}

The propagation prediction methods and related information concerning 'clear air' effects on terrestrial line-ofsight paths, earth-space paths (fixed, mobile, and broadcasting), and in the evaluation of interfering signal levels are derived from radio-meteorological data. However, detailed studies of system outage requires, in addition to the measurements made in this study, long-term measurements of electric field strength and path loss. Thus, the present work constitutes our initial efforts at making systematic empirical in-situ measurements for the study of microwave propagation in the lower atmosphere in this part of the world.

The plan is to continue the measurements with a view to building a data base of radio-meteorological data for microwave propagation studies in Nigeria. In addition to the above, the centre has acquired a new set of Micro Rain Radar (MRR) which would be used to collect rain data required to carry out studies on the effects of rain and other hydrometeors on earth-space propagation. The measurements will include rain rate and drop-size distribution from which the rain attenuation can be predicted. The MRR will also be used to observe the spatial variation of rain intensity, thus allowing the estimation of the attenuation along the propagation path. The study will also include observing spectrum of rain drop sizes which determines the rainfall rate, as well as the radar reflectivity and microwave radiation emission of the rain drops.

Open Access This article is distributed under the terms of the Creative Commons Attribution License which permits any use, distribution, and reproduction in any medium, provided the original author(s) and the source are credited.

\section{References}

Barclay L (2003) Propagation of radio-waves (2nd edition). The Institution of Electrical Engineers, London, pp 103-127

Bean BR, Dutton EJ (1968) Radio meteorology. Dover Publication Co, New York, pp 259-273

Bonkoungou Z, Low K (1993) Radio wave propagation measurement in Burkina Faso. SMR on radio wave propagation in tropical regions, Trieste, Italy

Falodun SE, Ajewole MO (2006) Radio refractive index in the lowest 100-m layer of the troposphere in Akure, South Western Nigeria. Journal of Atmospheric and Solar-Terrestrial Physics 68:236-243

Grabner M, Kvicera V (2003a) Refractive index measurement at TV tower Prague. Radio Eng 12(1):5-7

Grabner M, Kvicera V (2003b) Clear-air propagation modeling using parabolic equation method. Radio Eng 12(4):50-54

Hall MPM (1979) Effect of the troposphere on radio communication (IEE electromagnetic waves series). Peter Peregrinus Ltd, UK, pp $105-116$

Hughes KA (1988) CCIR propagation studies for Africa. ITU Telecommun J 55(1/1988):50-66

ITU-R (1987) The radio refractive index; its formula and refractivity data. Rec. 370 ITU-R 453-456 pp

Kolawole LB, Owonubi JJ (1982) The surface radio refractivity over Africa. Nig J Sci 16(nos 1\&2):441-454

Rec. ITU-R P. 453-9 (2004) The radio refractive index: its formula and refractivity data $455-460 \mathrm{pp}$

Owolabi IE, Williams VA (1970) Surface radio refractivity patterns in Nigeria and the Southern Cameroon. J West Africa Science Association 1:3-17 